\title{
FOCAL FACIAL SPASMS ASSOCIATED WITH BENIGN PAROTID HYPERTROPHY
}

\author{
Paulo Eduardo Mestrinelli Carrilho', Carolina Ferraz de Paula ${ }^{3}$, \\ Emerson W.S. Soares' ${ }^{2}$ Orival Alves ${ }^{7}$
}

Compression of the facial nerve by a cerebellopontine angle mass lesion, or by aberrant arteries in the posterior fossa can produce repetitive clonic and tonic contractions of one side of the face'. Such condition is also observed after Bell's palsy as a tardive complication' ${ }^{2}$. In spite of being relatively uncommon, a specific VII nerve branch damage can eventually generate focal spasms ${ }^{3}$.

We report a patient with such manifestation after chronic compression of facial nerve in its parotid segment caused by a gland benign enlargement.

\section{CASE}

A Caucasian 47 years-old man, without previous diseases, suddenly developed clonic and, sometimes, tonic involuntary contractions of the right orbicular oris muscle. Even a smile could elicitate the spasms. Neurologic examination was unremarkable, but a right parotid enlargement was noticed. Magnetic resonance imaging (MRI) disclosed a parotid tumour which was initially considered to be an adenoma. The macroscopic aspect of the VII nerve with all its branches was normal and the hystopathological study disclosed only a benign parotid hypertrophy. After the surgery, the patient obtained a partial relief in his focal spasms. The Figure disclosed the local of surgery. The patient gave an informed consent for this publication.

\section{DISCUSSION}

Myoclonic jerking of the paraspinal muscles due to malignant tumours involving thoracic roots and focal myoclonus after lumbar laminectomy or lumbosacral radiculopathy, electric injury to the brachial plexus and other kind of peripheral nerve system damages are rare but well-known entities $^{1,3,4}$. A more common condition, hemifacial spasms can also be triggered by a VII nerve injury, usually by a mass lesion in the cerebellopontine angle but even in other sites related to the extra-cranial branches in the face ${ }^{1-3}$.

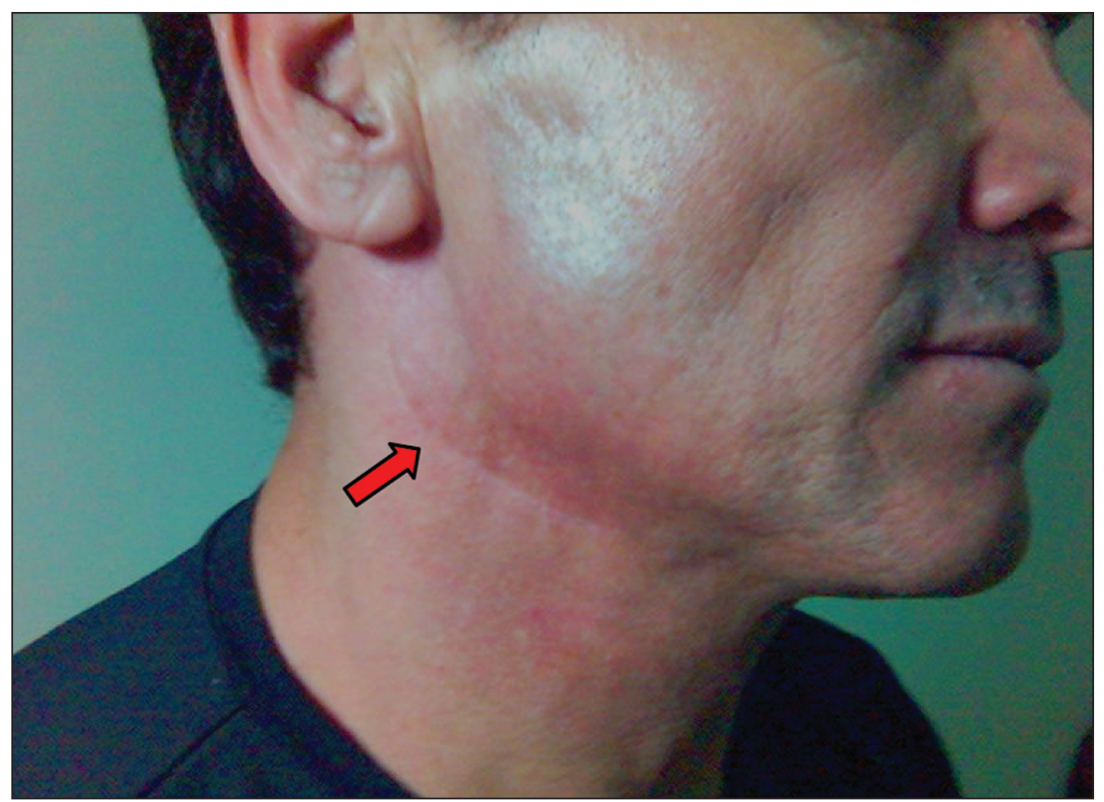

Figure. Red arrow indicates the topography of surgery.

\section{ESPASMOS FOCAIS FACIAIS ASSOCIADOS À HIPERTROFIA BENIGNA DA PARÓTIDA}

State University of West Paraná (UNIOESTE), PR, Brazil: 'Professor of Neurology and Neurosurgery; ${ }^{2}$ Professor of Propedeutic; ${ }^{3}$ Medicine Student. Received 17 August 2007, received in final form 19 November 2007. Accepted 3 January 2008.

Dr. Paulo E.M. Carrilho - Rua Santa Catarina 925 - 85801-040 Cascavel PR - Brasil. E-mail: pemcarrilho@gmail.com 
Multiple pathophysiological mechanisms are probably involved, including abnormal branching after aberrant axonal regeneration and enhaced facial motoneural excitability ${ }^{2}$. Local irritation of facial nerve causing ectopic excitation and ephatic transmission associated with demyelination may also be associated with the genesis of facial spasms ${ }^{5}$. However, other evidences suggest the presence of facial nerve nucleus hyperactivity in this condition ${ }^{6}$. Both theories can be combined. The partial lesion of the VII nerve, promoting ectopic excitation and ephatic transmission, results in both orthodromic and antidromic nerve activity associated with deafferentation, which can induce a reorganization of the nuclear neurons connections and activity².

Interestingly, in the present case, the lesion is confined to a specific VII nerve branch, promoting spasms in a very restricted area of orbicular oris. There were no mac- roscopic damage observed in the nerve or its branches, besides, there was an improvement after the surgery. We speculate that the ectopic and ephatic theory could be more prominent in the present case than the reorganization of VII nerve nucleus functions.

\section{REFERENCES}

1. Marsden CD. Peripheral movement disorders: In Marsden CD, Fahn S (Eds). Movement disorders 3. Butterworth-Heinemann, UK 1994:406-417.

2. Valls-Solé J, Montero J. Movement disorders in patient with peripheral facial palsy. Mov Disord 2003;18:1424-1436.

3. Martinelli P, Giuliani S, Ippoloti M. Hemifacial spasm due to peripheral injury of facial nerve: a nuclear syndrome? Mov Disord 1992;7:181-184.

4. Nóbrega JCM, Campos CR, Limongi JCP, Teixeira MJ, Yeng LT. Movement disorders induced by peripheral trauma. Arq Neuropsiquiatr 2002;60:17-20

5. Nielsen VK. Pathophysiology of hemifacial spasm I: ephatic transmission and ectopic excitation. Neurology 1984;34:418-426.

6. Valls-Solé J, Tolosa ES. Blink reflex excitability cycle in hemifacial spasm. Neurology 1989;39:1061-1066. 